\title{
Good Lives Model: Importance of Interagency Collaboration in Preventing Violent Recidivism
}

\author{
Jaimee Sheila Mallion
}

check for

updates

Citation: Mallion, J.S. Good Lives Model: Importance of Interagency Collaboration in Preventing Violent Recidivism. Societies 2021, 11, 96. https://doi.org/10.3390/soc11030096

Academic Editor: Gregor Wolbring

Received: 25 June 2021

Accepted: 9 August 2021

Published: 11 August 2021

Publisher's Note: MDPI stays neutral with regard to jurisdictional claims in published maps and institutional affiliations.

Copyright: (C) 2021 by the author. Licensee MDPI, Basel, Switzerland. This article is an open access article distributed under the terms and conditions of the Creative Commons Attribution (CC BY) license (https:// creativecommons.org/licenses/by/ $4.0 /)$.
Division of Psychology, School of Applied Sciences, London South Bank University, London SE1 0AA, UK; mallionj@lsbu.ac.uk

\begin{abstract}
Violence is a complex and multifaceted problem requiring a holistic and individualized response. The Good Lives Model (GLM) suggests violence occurs when an individual experiences internal and external obstacles in the pursuit of universal human needs (termed primary goods). With a twin focus, GLM-consistent interventions aim to promote attainment of primary goods, whilst simultaneously reducing risk of reoffending. This is achieved by improving an individuals' internal (i.e., skills and abilities) and external capacities (i.e., opportunities, environments, and resources). This paper proposes that collaborations between different agencies (e.g., psychological services, criminal justice systems, social services, education, community organizations, and healthcare) can support the attainment of primary goods through the provision of specialized skills and resources. Recommendations for ensuring interagency collaborations are effective are outlined, including embedding a project lead, regular interagency meetings and training, establishing information sharing procedures, and defining the role each agency plays in client care.
\end{abstract}

Keywords: good lives model; violence; intervention; interagency collaboration

\section{Introduction}

Violence is a pervasive problem affecting all communities world-wide, with nearly half a million people losing their lives to intentional homicide annually [1]. Critically, this figure is on the rise: between 2015 and 2017, a four percent increase in homicide rates was recorded globally [2]. However, intentional homicide is only one form of interpersonal violence. As defined by the World Health Organization [3], violence is "the intentional use of physical force or power, threatened or actual, against oneself, another person, or against a group or community, that either results in or has a high likelihood of resulting in injury, death, psychological harm, maldevelopment or deprivation". Thus, violence incorporates acts of physical, sexual, and/or psychological abuse [4], of which homicide is not often the primary outcome.

Violence has a long-term impact on the lives of many individuals. For instance, one third of women have experienced violence from an intimate partner (IPV) during their lifetime [5], whilst approximately one billion children (aged 2-17 years) have experienced abuse in the past year [6]. In addition to the risk of serious physical harm, these acts of violence are associated with a variety of poor outcomes for the victims, including high rates of depression, anxiety, PTSD, substance misuse, and suicidality [7]. Furthermore, individuals exposed to violence are more likely to have difficulty securing and maintaining employment and be at risk of poor health outcomes later in life (i.e., health conditions related to poor coping strategies and health risk behaviors, such as diabetes, strokes, and heart attacks [8]). This highlights that the consequences of violence are long reaching, continuing to affect victims throughout their lifetime.

In addition to the direct impact on the victim, the outcomes of violence are wide reaching, deeply impacting families, friends, and communities [4]. For instance, youth violence has been well-recognized for its impact on the wider community. In areas with 
high rates of youth violence, community members report decreased feelings of safety, normalization of violence, and increased community stigmatization which, in turn, reduce education and employment opportunities [9]. Critically, this leads to a cyclic pattern of violent behavior, whereby younger members of the community perceive violence as an acceptable and readily available option $[10,11]$. Those that engage in youth violence are also more likely to perpetrate IPV and child maltreatment than their non-violent counterparts $[12,13]$.

Previously, the pervasiveness of violence led to the perception that it was inevitable within human society, with it falling on law enforcement to respond to violent acts after the fact [4]. However, there has been a growing body of research surrounding the underlying causes of violent behavior. Taking a multifaceted approach, violence occurs from the interplay between the individual, family, peers, education, and community. Regarding the individual, factors such as impulsivity, poor emotion recognition, and substance misuse increase the risk of engaging in violence [14]. Familial incarceration, child maltreatment, and witnessing IPV are predictive factors of engaging in violent behavior [15-17]. Similarly, peer engagement in gangs, bullying, and peer substance misuse are risk factors for violence [18-20]. Regarding the education domain, poor relationships with teachers, suspension/exclusion from school, and a lack of academic attainment are associated with violent behavior [21-23]. Finally, residing in communities with high rates of violence, presence of gangs, and crime increase the risk of engaging in violent behavior [24].

As violence is a complex and multifaceted problem, there is no single solution for this issue. For too long, the response to violence (and its risk factors) has been fragmented [4]. To tackle violence, a 'whole-systems' approach is needed, whereby the various determinants (individual, family, education, peer, and community) are all examined and targeted. To enable this, a collaborative approach is necessary as various organizations have different skills, abilities, and resources, meaning they are more suited to support specific needs of an individual displaying violent behavior. For instance, social services (also known as child welfare agencies) would be best placed to provide family-based interventions, whilst educational services can advance an individual's training needs and improve access to employment. By pulling together these different organizations, this will enhance the effectiveness of violence prevention and intervention programs [25].

The aim of this paper is to emphasize the need for collaborative approaches to prevent and reduce violent behavior. To explore the benefits of interagency collaboration, it is first necessary to understand what factors can lead to engagement in violent behavior. The Good Lives Model (GLM) is one approach that can be used to understand this [26]. Unlike fragmented approaches to violence intervention, the GLM takes a holistic approach, viewing individuals as having a variety of needs/goals they are working towards attaining. When something goes wrong in the pursuit of these needs/goals, offending behavior (including violence) can occur [27]. As such, the GLM suggests that supporting individuals to attain primary goods through prosocial means will reduce the need to engage in violent behavior.

Critically, individuals present a variety of needs and goals, as well as obstacles preventing the prosocial attainment of these. Targeting all of these in an intervention can be beyond the scope of a single agency. As such, the current paper supports the assumption that interagency collaboration (i.e., collaboration between psychological services, criminal justice systems, social services, education, community organizations, and healthcare), when done well can enhance the effectiveness of violence interventions by improving access to specialized skills and resources [28]. This paper will first explain the assumptions of the GLM in relation to violent behavior. Second, the formulation and effectiveness of GLM-consistent interventions for violent behavior will be summarized. Third, research surrounding the effectiveness of interagency collaborations in offender interventions will be discussed. Finally, the implementation of interagency collaborations in GLM-consistent interventions for violent behavior will be considered, with recommendations made to carry this out effectively. 


\section{Good Lives Model: An Overview of Assumptions}

Devised as a strengths-based framework for offending behavior interventions, the GLM proposes that the risk of offending lessens when an individual has a sufficient level of capabilities and strengths to achieve their personal goals and needs [26,29]. According to the GLM, healthy human functioning is conceptualized as the pursuit of specific goals and needs (termed primary goods), which are fundamental for survival, establishing social networks, and reproducing [30]. These primary goods are prudential in nature; rather than inherently moral goods, primary goods are experiences, characteristics, and mental states that enable an individual to have a sense of fulfilment, well-being, and happiness [31]. Based on the literature surrounding human needs [32], 11 primary goods have been identified to date (see Table 1). These primary goods are multi-faceted, meaning each of the 11 primary goods resembles a cluster of smaller components (e.g., the primary good of Relatedness includes sub-goods of having a sense of love, intimacy, emotional connection, and friendship [27]).

Table 1. Definitions of 11 Primary Goods, according to the GLM.

\begin{tabular}{ccl}
\hline & Primary Good & \\
\hline 1 & Life & Basic needs for survival, physical well-being, and functioning. \\
\hline 2 & Knowledge & Feeling well informed about matters important to the individual. \\
\hline 3 & Excellence in Work & $\begin{array}{l}\text { Pursuing personally meaningful work that enables a sense } \\
\text { of mastery. }\end{array}$ \\
\hline 5 & Excellence in Play & $\begin{array}{l}\text { Pursuing recreational activities which gives a sense of enjoyment } \\
\text { and skill development. }\end{array}$ \\
\hline 6 & Community & $\begin{array}{l}\text { Having a sense of belonging with a wider social network, who } \\
\text { have similar interests and values. }\end{array}$ \\
\hline 7 & Relatedness & $\begin{array}{l}\text { Connecting with others in a warm and affectionate manner } \\
\text { (including intimate, romantic, and family relationships } \\
\text { and friendships). }\end{array}$ \\
\hline 9 & Inner Peace & $\begin{array}{l}\text { Feeling free from emotional turmoil and stress, and effectively } \\
\text { managing negative emotions. }\end{array}$ \\
\hline 10 & Pleasure & Sense of happiness and contentment in one's current life. \\
\hline 11 & Spirituality & Finding a sense of meaning and purpose in life. \\
\hline
\end{tabular}

Secondary goods (also known as instrumental goods) represent the ways in which individuals achieve their primary goods. For example, the primary good of Community could be secured by joining a neighborhood-led group (e.g., Scouts). However, the GLM suggests offending behaviors occur when primary goods cannot be adequately secured through prosocial means. This is due to weaknesses within the individual and/or their environment preventing them from achieving primary goods through appropriate methods, meaning inappropriate means are instead utilized [26]. For instance, an individual could attempt to gain a sense of Community by engaging in offending behaviors such as joining a street gang [33], which give individuals a sense of control over and status within their neighborhood, whilst simultaneously allowing them to create strong emotional connections with peers [34]. Similarly, sharing of violent and sexualized images online fosters feelings of belonging, enabling a sense of Community, as individuals connect with other like-minded people who share and validate their antisocial attitudes and beliefs [35].

Two routes leading to the use of offending behavior as a means of securing primary goods have been proposed [36]. Firstly, the direct pathway suggests offending behavior is actively utilized to attain primary goods. For example, an individual who lacks the 
capabilities to maintain healthy relationships may purposefully engage in violent and/or controlling behavior to prevent the relationship ending. Comparatively, according to the indirect pathway, in the pursuit of primary goods something goes awry which causes a cascading effect, resulting in offending behavior. For instance, if, when attempting to fulfil the primary good of Relatedness, an individual experiences peer rejection from prosocial groups, they may utilize maladaptive coping strategies (e.g., consumption of alcohol and drugs and/or associating with delinquent peers). The use of these maladaptive coping strategies then increases the likelihood of engaging in violent behavior [37]. Whilst violence can result from both the direct and indirect pathway, individuals' whose behavior was a product of the indirect pathway struggle most in understanding the causes of their offending behavior and may require more support to prevent recidivism [38].

To date, there have been four obstacles identified which can lead to difficulty fully attaining primary goods in a prosocial manner: use of inappropriate means, and a lack of scope, coherence, and/or capacity [39]. As highlighted above, when prosocial opportunities seem inaccessible, inappropriate means may be used in an attempt to attain primary goods. However, when antisocial secondary goods are used, the primary good is not fully secured, but 'pseudo-secured'. This means that the primary good is only secured temporarily (if at all), as it is continuously under threat. Take, for instance, an individual who secures their primary good of Relatedness by acting in a controlling and violent manner towards an intimate partner. Relatedness may be 'pseudo-secured' as the relationship continues due to the partner's fear of leaving, however, the warm, affectionate aspects are unlikely to be fully realized. Importantly, where primary goods are only pseudo-secured, the individual is left feeling frustrated, meaning the likelihood that they will have a happy, meaningful, and fulfilling life is low [36].

The second obstacle, coherence, refers to the need for primary goods to be ordered and rationally related to each other. Where coherence is lacking, individuals feel frustrated and struggle to find meaning and purpose in life [40]. Primary goods can be related either horizontally or vertically [26]. Horizontal coherence refers to a harmonious relationship between primary goods, where they complement and enable each other. However, when primary goods are not horizontally coherent, conflict between goods can occur, leading to the use of inappropriate means. For example, an individual may place an equally high level of importance on the attainment of both Relatedness and Excellence in Agency. To attain Relatedness, they establish a close and secure romantic relationship. However, this conflicts with the attainment of Excellence in Agency; if they have no other opportunities to exert their autonomy and independence, they may behave violently towards their intimate partner to gain this sense of power and control.

Comparatively, vertical coherence refers to ranking of primary goods according to their degree of importance [40]. The level of importance assigned to primary goods differs according to the person's preferences, as well as social and cultural norms, and is closely linked to the conceptualization of their personal identity. An individual's behavior should be informed by the degree of importance assigned to each, with primary goods rated as highly important given the most amount of attention. For example, someone who rates Inner Peace as most important is going to be unhappy if they instead attain Excellence in Work by working in an environment that causes a high degree of stress. If there is a paucity of vertical coherence, the individual feels unfulfilled and lacks a sense of meaning and purpose in life. Ward and Stewart [26] suggests this leads to the neglect of long-term goals, in favor of immediate gratification. Thus, continuing with the previous example, the individual could attempt to relieve the stress from work (and attain Inner Peace) by expressing their emotions through negative means (i.e., acting violently, either towards themselves or others).

Although the level of importance differs for each primary good, all primary goods must be attained (to some degree) for a happy and meaningful life [27]. Neglecting or failing to strive for a primary good is considered a lack of scope [41]. Whilst disinterest plays a role in the neglect of primary goods, problems in capacity (i.e., skills and resources) 
tend to be the leading cause of a lack of scope. For instance, an individual with poor communication skills would (at a minimum) have difficulty securing the primary goods of Relatedness and Community. As a result of the frustration caused, the individual may engage in violent behavior. Supporting this, a review of factors for perpetrating IPV found $48 \%$ of studies included communication difficulties as a common motive [42].

The final obstacle, lack of capacity, refers to an individual experiencing a deficit in their internal skills and abilities (cognitive, psychological, and/or behavioral) or external resources (i.e., opportunities and/or environments) necessary to attain their primary goods. It must be noted that capacity issues are synonymous with 'criminogenic needs' (as used in the wider literature [40]). Both internal and external capacity issues have been identified as causal factors in violent behavior [43]. Regarding internal capacity issues, violent behavior has been associated with (among other factors) poor emotion regulation abilities, oppositional behaviors, impulsivity, callous-unemotional traits, and mental illness [44,45]. Furthermore, poverty, lack of employment opportunities, witnessing familial conflict, exposure to community violence and having antisocial peers are examples of external capacity issues that can lead an individual to engage in violent behavior $[46,47]$.

When an individual experiences internal and external capacity issues, this can prevent the attainment of primary goods through prosocial means. For instance, past research has suggested that individuals exhibiting oppositional behaviors have difficulty securing and maintaining employment [48], supporting the assumption that attainment of Excellence in Work is prevented by issues in internal capacity. Concerning external capacity issues, if an individual lives in an area where competition for employment is high, this can equally prevent attainment of Excellence in Work. If the individual is unable to find a prosocial means of achieving the primary goods, then antisocial means may be used in an attempt to fulfil these (e.g., joining a gang as a form of 'employment' [49]). This highlights that internal and external capacity issues can prevent attainment of primary goods, with failure leading to frustration and engagement in violence. Critically, an individual is most vulnerable to engaging in violence if they are exposed to multiple internal and external capacity issues [40].

\section{Good Lives Model: A Framework for Violence Intervention}

As an intervention framework, the GLM guides the development and implementation of evidence-based interventions by emphasizing adherence to GLM-consistent treatment assumptions [50]. The key assumption guiding GLM-consistent treatment is that dualfocus should be placed on promoting prosocial attainment of primary goods, whilst also reducing risk of violence [51]. The GLM is considered a strengths-based approach to violence intervention, whereby an individual's personal strengths, goals, and interests are considered and built upon. When support is given to attain primary goods, through enhancing internal skills and providing external opportunities and resources, this should simultaneously lead to a reduction in violent behavior. Ultimately, the aim of GLMconsistent treatment is to help individuals attain a 'good life': one which is both personally meaningful and socially acceptable [39].

This differs from risk-based approaches to violence intervention, as GLM-consistent treatment aims to replace what is lost when violent behavior ceases [50]. Take the analogy of a pincushion: if all pins are removed but there is nothing to replace them, then the cushion will be left full of holes. Similarly, if all risk factors (e.g., spending time with antisocial peers and engaging in substance misuse) are removed, without providing an alternative means of achieving primary goods, an individual will be left frustrated and unhappy [26]. Therefore, in addition to reducing violent behavior, supporting the successful attainment of primary goods through prosocial means should lead to improvements in an individual's overall well-being, with increased happiness and reduced frustration [27].

When providing GLM-consistent treatment to an individual exhibiting violent behavior, a clinical interview should initially be conducted with the client. For examples of questions used to guide the clinical interview, see Griffin and Wylie [52]. The aims of the 
clinical interview are to explore: (a) how primary goods were sought at the time of the violent episode(s), (b) what secondary goods were used to attain primary goods, (c) issues in means, scope, coherence, and capacity, (d) personal strengths (i.e., internal capacities) and means (i.e., external capacities) currently available to the client, and (e) contexts or environments the client will be exposed to throughout and following an intervention. This leads to the creation of an individualized action plan, termed a 'Good Lives Plan', which highlights the skills and resources that should be targeted during interventions to enable attainment of primary goods through prosocial means. Collaboration between the client and therapist is essential in the creation of a Good Lives Plan. This encourages focus on primary goods of importance to the individual and enables the formulation of personally meaningful goals (short, medium, and long term), ensuring the Good Lives Plan is motivational and achievable [39].

As an intervention framework, the GLM can wrap around existing evidence-based treatment programs. Therefore, a Good Lives Plan guides which treatment programs (e.g., Cognitive Behavioral Therapy, Functional Family Therapy, substance use groups), skills programs (e.g., educational programs, apprenticeships) and/or external resources (e.g., access to employment opportunities, health care, prosocial support networks) would be most appropriate for a client to receive. Furthermore, the GLM informs how these treatment programs should be implemented, with considerations given to the ethics, goal formation, language used, and therapist characteristics. Specifically, GLM-consistent treatment should emphasize the client's agency, autonomy, and dignity [31]. In addition, GLM-consistent treatment should also utilize approach (rather than avoidance) goals, which highlight that a future without violence is both achievable and attractive [39]. Consistent with a strengthsbased approach, the GLM expects positively framed language to be used throughout treatment programs, whereby focus is placed on skills rather than deficits of a client [26]. Finally, therapists are encouraged to demonstrate empathy, warmth, and respect towards clients, which aids in building a strong therapeutic alliance [53].

The GLM is frequently used to guide offender intervention world-wide and has been applied to numerous offending typologies including sexual offences, IPV, gang membership, and general violence [49,54-56]. A systematic review found GLM-consistent interventions were at least as effective as standard relapse prevention programs [57]. Specifically, pre-post measures of psychometric change did not differ between GLM-consistent and relapse prevention interventions [58,59]. In addition, clients that received GLM-consistent treatment report reduced feelings of shame, hopelessness, and defensiveness, and increased optimism for the future, confidence, perspective-taking ability, trust of others, and selfawareness [60,61]. Furthermore, in a case study, Whitehead et al. [55] discussed a high-risk violent offender who had received a GLM-consistent intervention. The client was supported to attain their primary goods, including engaging in education, pursuing new leisure activities, and maintaining a committed relationship. At a six-year follow-up, the client had not committed any further offences and had reduced engagement with street gang peers [62]. Of note, the client had previously received two intensive risk-oriented interventions but had continued to recidivate. This demonstrates that the GLM-consistent intervention was more successful in reducing violent behavior than risk-based interventions.

Findings from the only randomized control trial to date suggest participants who received GLM-consistent interventions demonstrated a greater motivation to desist from offending (as rated by therapists), had increased treatment engagement, and were more willing to disclose any lapses in behavior than participants that received standard relapse prevention treatment [63]. Whilst this supports the use of GLM-consistent interventions, it must be noted that the evidence-base remains in its infancy and primarily focuses on interventions for sexual offending. Critically, as the GLM is the preferred framework for offender intervention in one third of programs in the USA and half of programs in Canada [64], it is expected that the research base regarding the effectiveness of GLMconsistent interventions will rapidly increase in the coming years. 


\section{Interagency Collaboration in Violence Intervention}

Clients with a history of violent behavior often present with multiple internal and external obstacles that prevent attainment of primary goods through prosocial means [49]. The clients' needs span multiple domains (e.g., individual, family, peer, education, and community), meaning multifaceted solutions are required to support attainment of primary goods and reduce violent recidivism [65]. Effectively responding to the complex and interrelated needs of a client is beyond the scope of a single organization and has led to the call for interagency collaboration [66]. To clarify, in this paper, interagency collaboration is defined as the coordinated effort of various organizations in achieving a common goal, such as violence prevention [67].

The primary benefit of interagency collaboration is improved access to different expertise and resources, which enables a holistic approach to client care [68]. With the common goal being the reduction of violence, a variety of agencies have specialized skills that could increase the possibility of fulfilling this. Social services, healthcare, criminal justice systems, education, community services, and psychological therapists are just a few examples of specialist agencies that can play a key role in violence interventions. For example, social services have the resources and expertise available to provide family-based interventions, healthcare services can support physical wellbeing, and community services can support the attainment of practical needs (e.g., housing and employment).

To date, research has suggested that interagency collaboration is crucial in both reducing rates of incarceration and preventing violent recidivism [65]. Interventions which utilize interagency collaboration also have higher retention rates and clients demonstrating reduced reliance on substances [69]. Furthermore, parents report their child exhibits improved attitudes, reduced risk-taking and antisocial behavior, and improved family relationships after receiving treatment from youth offending programs with interagency collaboration [70]. Regarding violence intervention specifically, programs with interagency collaboration have led to a significant reduction in violent behavior [71]. For example, the Cincinnati Initiative to Reduce Violence (CIRV) involved an interagency collaboration between law enforcement, community services (e.g., street advocates), healthcare professionals, researchers, and businesses, resulting in a $61 \%$ reduction in violence. The impact of CIRV on reducing gang-related homicides and violent firearm offences was maintained for a 42-month follow-up time [72].

Critically, most research on the effectiveness of programs incorporating interagency collaboration suffers from a lack of control group. Overcoming this, Pullman et al. [73] compared youth offenders receiving mental health treatment with an interagency collaboration to a control group of youth offenders receiving mental health treatment without interagency collaboration. Compared to the control, youth offenders receiving interagency treatment were less likely to reoffend and spent less time incarcerated. In addition, significant improvements in functioning at home, school, and in the community, and reduced emotional and behavioral problems were experienced by youth offenders receiving interagency treatment. With the growth in research supporting interagency collaboration, this is now advocated as 'best-practice' for offender interventions, including violence prevention, internationally $[74,75]$.

Despite this, Statham [76] purports that interagency collaboration is "not inherently a good thing" (p. 4). Specifically, when interagency collaboration is done well, the effectiveness of offender interventions improves. However, when interagency collaboration is poorly implemented, this can have a negative impact on outcomes of offender interventions [77]. A multitude of barriers have been identified which can prevent the effective implementation of interventions with an interagency collaboration. According to Cooper et al. [78], the most common barriers are poor communication and trust between agencies, confidentiality issues, and a lack of time and resources. In addition, fundamental differences in values, goals, and methods between agencies can significantly hinder the implementation and success of collaborative approaches to offender intervention [79]. For instance, in their evaluation of an interagency approach to violence intervention (incorpo- 
rating police, social services and community organizations), Gripp et al. [71] found initial resistance among police towards the collaboration, with officers describing the initiative as "another hug-a-thug program" (p. 50).

Whilst barriers do exist and are important to recognize, there are several factors that can facilitate good interagency collaboration. Firstly, having an open line of communication can improve relationships and trust between agencies. Researchers suggest monthly meetings between agencies to discuss clients' progress and share information are key for establishing positive communication [77]. Appointing a project manager can further enhance communication by balancing multiple and, at times, conflictual points of view [71]. Furthermore, joint training opportunities can improve understanding of the overarching goals, philosophy, and procedures surrounding offender intervention programs, emphasizing the benefits of working collaboratively [80]. In addition, procedures regarding information sharing and confidentiality need to be made clear to all agencies and clients at the beginning of an offender intervention program [81]. When implemented properly, interagency collaborations are the most effective means of delivering a holistic and responsive service for clients engaging in interventions for violent behavior [28].

\section{Interagency Collaboration in Good Lives Interventions}

The GLM is one intervention framework that emphasizes and, to some degree, relies on support from interagency collaborations. With 11 primary goods covering a diversity of needs, helping a client to attain these would be beyond the expertise of a single agency. As all primary goods must be attained for a fulfilling and meaningful life [27], it is important that some are not neglected simply due to the expertise of the agency leading client care. For example, psychological services have the expertise and resources available to support clients in overcoming internal capacity obstacles (e.g., developing coping strategies, improving mental health and interpersonal skills). This can lead to the attainment of primary goods such as Inner Peace and Relatedness. However, when working independently, psychological services may not have the resources available to target all external obstacles (e.g., access to housing, education, and employment opportunities), which can lead to some primary goods being neglected. When working in partnership with other agencies, this gap in expertise and resources can be filled.

At first glance, it may seem obvious which agencies are needed to aid in the attainment of primary goods. For instance, the primary good of Life (i.e., possessing the basic needs for survival, physical well-being, and functioning) may be attained by support from health care (i.e., ensuring physical well-being) or housing (i.e., shelter as a basic need) services. However, it is important to look beyond this over-simplified classification of the primary goods and focus on the capacity obstacles each client is experiencing. Specifically, a client with depression may neglect to care for their physical well-being [82], preventing the attainment of Life. Therefore, this client would require support from agencies specializing in psychological therapies. This demonstrates the need for an individualized approach to violence intervention, with the degree of input from different agencies dependent on the individuals' Good Lives Plan.

When developing a violence intervention consistent with GLM assumptions, it is recommended that these steps are first followed:

(1) Identify agencies that would be beneficial to a collaborative approach. This could include psychological services, criminal justice services (e.g., probation, police, prison service), social services, education, housing, community organizations (e.g., employment/volunteering), or healthcare. As explained above, the degree of input required from each agency will differ depending on the client, with some clients needing a great deal of input from agencies, whilst others require little to no support. However, establishing good contact with a variety of agencies during the planning stages of an intervention will prevent any delay in client care.

(2) Provide interagency training explaining the assumptions of the GLM and goals of GLM-consistent interventions. Some agencies may be used to a risk approach to 
violence intervention with avoidance-focused goals. It is important to emphasize in training that the GLM advocates the use of a strengths-based method, with approachfocused goals, and that this must remain consistent throughout the intervention.

(3) Embed a project lead to enhance communication and balance differing values and goals across agencies. The project lead should have expertise in the GLM to ensure that the intervention planning remains consistent with the assumptions of the GLM (i.e., focus on developing strengths, overcoming internal and external capacity obstacles, ensuring a well-rounded intervention incorporating all primary goods).

(4) Discuss confidentiality and information sharing issues/caveats and establish the procedures surrounding this.

Regarding the implementation of a GLM-consistent intervention with clients, it is recommended that this procedure is followed:

(1) Therapist specializing in the GLM conducts a clinical interview with the client exploring: (a) how primary goods were sought at the time of the violent episode(s), (b) what secondary goods were used to attain primary goods, (c) issues in means, scope, coherence, and capacity, (d) personal strengths (i.e., internal capacities) and means (i.e., external capacities) currently available to the client, and (e) contexts or environments the client will be exposed to throughout and following an intervention.

(2) In collaboration with the client, create a Good Lives Plan. This should be a strengthsfocused action plan, incorporating an individual's goals that, if attained, would enable them to have a meaningful and happy life without the need to offend. A Good Lives Plan should be realistic and achievable; whilst long-term goals are important, incremental attainable steps should be included. This enables a sense of achievement and supports motivation to pursue longer-term goals. Furthermore, the clients support networks, environments, and capacity should be considered when developing a Good Lives Plan, as this will impact upon how attainable goals are.

(3) Based on the clients' Good Lives Plan, the therapist formulates an intervention strategy. This highlights the obstacles (both internal and external) preventing effective attainment of primary goods that need targeting during an intervention and highlights which agencies would be best placed to support the client with each obstacle. It is likely that support from multiple agencies will be needed. For instance, a client may be unable to attain the primary good of Life due to homelessness, meaning support from community housing services is necessary. In addition, they may engage in violent behavior to express negative emotions (i.e., attain Inner Peace), which indicates support is needed from psychological services.

(4) Regular meetings between agencies (at least once a month) should be implemented to ensure continuity in client care and sharing of information regarding progress. Critically, as a client's goals or obstacles can change, be attained, or overcome, a Good Lives Plan should be viewed as a dynamic and adaptable tool that guides and supports therapeutic work. As such, good communication between agencies involved in client care is vital.

Interagency collaboration provides a well-rounded approach to violence intervention, with the provision of expertise and resources beyond that which a single agency could offer. Ultimately, this will further support the client in overcoming various internal and external capacity obstacles which can lead to their violent behavior. This will simultaneously lead to a reduction in the criminogenic needs of the client, reducing their likelihood of engaging in violence in the future [50]. Importantly, this will also support the attainment of each of the 11 primary goods, which will enable the client to have a life which is both personally meaningful and socially acceptable [39].

\section{Conclusions}

The response to violence has primarily been risk-focused and fragmented [4]. Theorists have argued that risk-focused frameworks have reached a "glass-ceiling", whereby further refining of interventions will not equate to reductions in reoffending [83]. As such, 
strengths-based approaches to violence intervention, including the GLM, are growing in popularity. The GLM recognizes the complexity of human behavior, suggesting violence occurs due to obstacles (internal and external) experienced in the pursuit of primary goods. By supporting clients to overcome these obstacles and effectively attain their primary goods, the GLM assumes that this will simultaneously lead to a reduction in violent behavior.

As each client will face various internal and external obstacles, interagency collaborations can provide the skills and resources necessary to assist in overcoming these, enabling the attainment of primary goods through prosocial means. Whilst barriers have been highlighted in past research [78], several recommendations can be made to support the implementation of an effective interagency collaboration. These include embedding a project lead to support good communication between agencies, holding regular interagency meetings, providing regular interagency training, defining the role each agency plays in client care, and establishing information sharing and confidentiality procedures at an early stage [77]. If done well, interagency collaboration can support clients to have a happy and meaningful life, free from violence.

Funding: This research received no external funding.

Institutional Review Board Statement: Not applicable, no participants involved, theoretical only.

Informed Consent Statement: Not applicable, no participants involved, theoretical only.

Conflicts of Interest: The author declares no conflict of interest.

\section{References}

1. World Health Organization. Injuries and Violence: The Facts. 2014. Available online: https://apps.who.int/iris/handle/10665/ 149798 (accessed on 23 June 2021).

2. United Nations Office on Drugs and Crime. Available online: https:/ / www.unodc.org (accessed on 23 June 2021).

3. World Health Organization. Violence: A Public Health Priority. 1996. Available online: https://apps.who.int/iris/handle/1066 5/179463 (accessed on 23 June 2021).

4. World Health Organization. World Report on Violence and Health. 2002. Available online: http://apps.who.int/iris/bitstream/ handle/10665/42495/9241545615_eng.pdf?sequence=1 (accessed on 23 June 2021).

5. World Health Organization. Violence against Women. 2021. Available online: https://www.who.int/news-room/fact-sheets/ detail/violence-against-women (accessed on 23 June 2021).

6. Hillis, S.; Mercy, J.; Amobi, A.; Kress, H. Global prevalence of past-year violence against children: A systematic review and minimum estimates. Pediatrics 2016, 137, 1-22. [CrossRef]

7. Spencer, C.; Mallory, A.B.; Cafferky, B.M.; Kimmes, J.G.; Beck, A.R.; Stith, S.M. Mental health factors and intimate partner violence perpetration and victimization: A meta-analysis. Psychol. Violence 2019, 9, 1-17. [CrossRef]

8. Black, M.C. Intimate partner violence and adverse health consequences: Implications for clinicians. Anal. Rev. 2011, 5, 428-439. [CrossRef]

9. Adams, E.B.; Morris, P.K.; Maguire, E.R. The impact of gangs on community life in Trinidad. Race Justice 2018, 1, 1-24. [CrossRef]

10. Nofziger, S.; Kurtz, D. Violent lives: A lifestyle model linking exposure to violence to juvenile violent offending. J. Res. Crime Delinq. 2005, 42, 3-26. [CrossRef]

11. Rowan, Z.R.; Schubert, C.A.; Loughran, T.A.; Mulvey, E.P.; Pardini, D.A. Proximal predictors of gun violence among adolescent males involved in crime. Law Hum. Behav. 2019, 43, 250-262. [CrossRef]

12. Augustyn, M.B.; Thornberry, T.P.; Krohn, M.D. Gang membership and pathways to maladaptive parenting. J. Res. Adolesc. 2014, 24, 252-267. [CrossRef]

13. Nydegger, L.A.; DiFranceisco, W.; Quinn, K.; Dickson-Gomez, J. Gender norms and age-disparate sexual relationships as predictors of intimate partner violence, sexual violence, and risky sex among adolescent gang members. J. Urban Health 2017, 94, 266-275. [CrossRef] [PubMed]

14. DeLisi, M.; Drury, A.J.; Elbert, M.J. Do behavioral disorders render gang status spurious? New insights. Int. J. Law Psychiatry 2019, 62, 117-124. [CrossRef] [PubMed]

15. Forke, C.M.; Myers, R.K.; Fein, J.A.; Catallozzi, M.; Localio, A.R.; Wiebe, D.J.; Grisso, J.A. Witnessing intimate partner violence as a child: How boys and girls model their parents' behaviors in adolescence. Child Abus. Neglec. 2018, 84, 241-252.

16. Klein, M.W.; Maxson, C.L. Street Gang Patterns and Policies; Oxford University Press: Oxford, UK, 2006.

17. Muftić, L.R.; Smith, M. Sex, parental incarceration, and violence perpetration among a sample of young adults. J. Interpers. Violence 2018, 33, 316-338. [CrossRef]

18. Alleyne, E.; Wood, J.L. Gang-related crime: The social, psychological and behavioral correlates. Psychol. Crime Law 2013, 19, 611-627. [CrossRef] 
19. O'Brien, K.; Daffern, M.; Chu, C.M.; Thomas, S.D.M. Youth gang affiliation, violence, and criminal activities: A review of motivational, risk, and protective factors. Aggress. Violent Behav. 2013, 18, 417-425. [CrossRef]

20. Ttofi, M.M.; Farrington, D.P.; Lösel, F. School bullying as a predictor of violence later in life: A systematic review and meta-analysis of prospective longitudinal studies. Aggress. Violent Behav. 2012, 17, 405-418. [CrossRef]

21. Rosenbaum, J. Educational and criminal justice outcomes 12 years after school suspension. Youth Soc. 2020, 52, 515-547. [CrossRef] [PubMed]

22. Savage, J.; Ellis, S.K. Academic achievement, school attachment, and school problems in the differential etiology of violence. J. Dev. Life Course Criminol. 2019, 5, 243-265. [CrossRef]

23. Volungis, A.M.; Goodman, K. School violence prevention: Teachers establishing relationships with students using counseling strategies. Sage Open 2017, 7, 1-11. [CrossRef]

24. Franzese, R.J.; Menard, S.; Weiss, A.J.; Covey, H.C. Adolescent exposure to violence and adult violent victimization and offending. Crim. Justice Rev. 2017, 42, 42-57. [CrossRef]

25. Public Health England. A Whole-System Multi-Agency Approach to Serious Violence Prevention. 2019. Available online: https:/ /assets.publishing.service.gov.uk/government/uploads/system/uploads/attachment_data/file/862794/multiagency_approach_to_serious_violence_prevention.pdf (accessed on 23 June 2021).

26. Ward, T.; Stewart, C. The relationship between human needs and criminogenic needs. Psychol. Crime Law 2003, 9, $219-224$. [CrossRef]

27. Ward, T.; Maruna, S. Rehabilitation: Beyond the Risk Paradigm; Routledge: Oxford, UK, 2007.

28. Banks, D.; Dutch, N.; Wang, K. Collaborative efforts to improve system response to families who are experiencing child maltreatment and domestic violence. J. Interpers. Violence 2008, 23, 876-902. [CrossRef]

29. Ward, T. Good Lives and the rehabilitation of offenders: Promises and problems. Aggress. Violent Behav. 2002, 7, 513-528. [CrossRef]

30. Laws, D.R.; Ward, T. Desistance from Sex Offender: Alternatives to Throwing Away the Keys; The Guildford Press: New York, NY, USA, 2011.

31. Ward, T.; Syversen, K. Human dignity and vulnerable agency: An ethical framework for forensic practice. Aggress. Violent Behav. 2009, 14, 94-105. [CrossRef]

32. Deci, E.L.; Ryan, R.M. The 'what' and 'why' of goal pursuits: Human needs and the self-determination of behavior. Psychol. Inq. 2000, 11, 227-268. [CrossRef]

33. Mallion, J.S. Application of Good Lives Model to Street Gang Members. Ph.D. Thesis, University of Kent, Canterbury, UK, 2021.

34. Alleyne, E.; Wood, J.L. Gang involvement: Psychological and behavioral characteristics of gang members, peripheral youth, and nongang youth. Aggress. Behav. 2010, 36, 423-436. [CrossRef]

35. Kloess, J.A.; Beech, A.R.; Harkins, L. Online child sexual exploitation: Prevalence, process, and offender characteristics. Trauma Violence Abus. 2014, 15, 126-139. [CrossRef] [PubMed]

36. Purvis, M. Seeking a Good Life: Human Goods and Sexual Offending; Lambert Academic Press: Chisinau, Moldova, 2010.

37. Higgins, G.E.; Piquero, N.L.; Piquero, A.R. General strain theory, peer rejection, and delinquency/crime. Youth Soc. 2011, 43, 1272-1297. [CrossRef]

38. Gannon, T.A.; King, T.; Miles, H.; Lockerbie, L.; Willis, G.M. Good Lives sexual offender treatment for mentally disordered offenders. Br. J. Forensic Pract. 2011, 13, 153-168. [CrossRef]

39. Ward, T.; Fortune, C.A. The Good Lives Model: Aligning risk reduction with promoting offenders' personal goals. Eur. J. Probat. 2013, 5, 29-46. [CrossRef]

40. Purvis, M.; Ward, T.; Willis, G. The Good Lives Model in practice: Offence pathways and case management. Eur. J. Probat. 2013, 5, 29-46. [CrossRef]

41. Chu, C.M.; Koh, L.L.; Zeng, G.; Teoh, J. Youth who sexual offended: Primary human goods and offense pathways. Sex. Abus. 2015, 27, 151-172. [CrossRef]

42. Langhinrichsen-Rohling, J.; McCullars, A.; Misra, T. Motivation for men and women's intimate partner violence perpetration: A comprehensive review. Partn. Abus. 2012, 3, 429-468. [CrossRef]

43. Bernat, D.H.; Oakes, M.; Pettingell, S.L.; Resnick, M. Risk and direct protective factors for youth violence: Results from the national longitudinal study of adolescent health. Am. J. Prev. Med. 2012, 43, 57-66. [CrossRef]

44. Romero-Martínez, Á.; Lila, M.; Moya-Albiol, L. The importance of impulsivity and attention switching deficits in perpetrators convicted for intimate partner violence. Aggress. Behav. 2019, 45, 129-138. [CrossRef]

45. Wood, J.L.; Kallis, C.; Coid, J.W. Differentiating gang members, gang affiliates and violent men on their psychiatric morbidity and traumatic experiences. Psychiatry 2017, 80, 221-235.

46. Dishion, T.J.; Véronneau, M.-H.; Myers, M. Cascading peer dynamics underlying the progression from problem behavior to violence in early to late adolescence. Dev. Psychopathol. 2010, 22, 603-619. [CrossRef]

47. Park, S.; Kim, S.-H. The power of family and community factors in predicting dating violence: A meta-analysis. Aggress. Violent Behav. 2018, 40, 19-28. [CrossRef]

48. Burke, J.D.; Rowe, R.; Boylan, K. Functional outcomes of child and adolescent oppositional defiant disorder symptoms in young adult men. J. Child Psychol. Psychiatry 2014, 55, 264-272. [CrossRef] [PubMed] 
49. Mallion, J.S.; Wood, J.L. Good Lives Model and street gang membership: A review and application. Aggress. Violent Behav. 2020, 52, 1-11. [CrossRef]

50. Ward, T.; Yates, P.M.; Willis, G.M. The Good Lives Model and the Risk Need Responsivity Model: A response to Andrews, Bonta, and Wormith (2011). Crim. Justice Behav. 2012, 39, 94-110. [CrossRef]

51. Ward, T.; Gannon, T.A. Rehabilitation, etiology, and self-regulation: The comprehensive good lives model of treatment for sexual offenders. Aggress. Violent Behav. 2006, 11,77-94. [CrossRef]

52. Griffin, M.L.; Wylie, H. The journey: G-map's adaptation of the Good Lives Model. In The Good Lives Model for Adolescents Who Sexually Harm; Print, B., Ward, T., Eds.; The Safer Society Press: Brandon, VT, USA, 2013; pp. 35-54.

53. Barnao, M.; Ward, T.; Robertson, P. The Good Lives Model: A new paradigm for forensic mental health. Psychiatry Psychol. Law 2015, 23, 288-301. [CrossRef]

54. Langlands, R.L.; Ward, T.; Gilchrist, E. Applying the Good Lives Model to male perpetrators of domestic violence. Behav. Chang. 2009, 26, 113-129. [CrossRef]

55. Whitehead, P.R.; Ward, T.; Collie, R.M. Time for a change: Applying the good lives model of rehabilitation to a high-risk violent offender. Int. J. Offender Ther. Comp. Criminol. 2007, 51, 578-598. [CrossRef] [PubMed]

56. Willis, G.M.; Prescott, D.S.; Yates, P.M. The Good Lives Model (GLM) in theory and practice. Sex. Abus. Aust. New Zealand 2013, $5,3-9$.

57. Mallion, J.S.; Wood, J.L.; Mallion, A. Systematic review of 'Good Lives' assumptions and interventions. Aggress. Violent Behav. 2020, 55, 1-17. [CrossRef]

58. Harkins, L.; Flak, V.E.; Beech, A.R.; Woodhams, J. Evaluation of a community-based sex offender treatment program using a good lives model approach. Sex. Abus. 2012, 24, 519-543. [CrossRef]

59. Barnett, G.D.; Manderville-Norden, R.; Rakestrow, J. The Good Lives Model or relapse prevention: What works better in facilitating change? Sex. Abus. 2014, 26, 3-33. [CrossRef]

60. Leeson, S.; Adshead, M. The response of adolescents and practitioners to a Good Lives approach. In The Good Lives Model for Adolescents who Sexually Harm; Print, B., Ward, T., Eds.; The Safer Society Press: Brandon, VT, USA, 2013; pp. $183-193$.

61. Ward, M.; Attwell, P. Evaluation of two community outreach forensic psychological services. J. Forensic Pract. 2014, 16, 312-326. [CrossRef]

62. Willis, G.M.; Ward, T. The Good Lives Model: Does it work? Preliminary evidence. In What Works in Offender Rehabilitation: An Evidence-Based Approach to Assessment and Treatment; Craig, A., Dixon, L., Gannon, T.A., Eds.; John Wiley \& Sons: Hoboken, NJ, USA, 2013; pp. 305-317.

63. Mann, R.E.; Webster, S.D.; Schofield, C.; Marshall, W.L. Approach versus avoidance goals in relapse prevention with sexual offenders. Sex. Abus. J. Res. Treat. 2004, 16, 65-75. [CrossRef]

64. McGrath, R.J.; Cumming, G.F.; Burchard, B.L.; Zeoli, S.; Ellerby, L. Current Practices and Emerging Trends in Sexual Abuser Management. 2009. Available online: http://www.robertmcgrath.us/files/6414/3204/5288/2009_Safer_Society_North_American_ Survey.pdf (accessed on 24 June 2021).

65. Rocha, P. Meeting criminogenic needs to reduce recidivism: The diversion of vulnerable offenders from the criminal justice system into care. Int. J. Law Political Sci. 2019, 13, 831-837.

66. Nicholson, D.; Artz, S.; Armitage, A.; Fagan, J. Working relationships and outcomes in multidisciplinary collaborative practice settings. In Child and Youth Care Forum; Kluwer Academic Publishers-Plenum Publishers: Norwell, MA, USA, 2000; Volume 29, pp. 39-73.

67. Fletcher, B.W.; Lehman, W.E.; Wexler, H.K.; Melnick, G.; Taxman, F.S.; Young, D.W. Measuring collaboration and integration activities in criminal justice and substance abuse treatment agencies. Drug Alcohol Depend. 2009, 103, 54-64. [CrossRef]

68. Strype, J.; Gundhus, H.I.; Egge, M.; Ødegård, A. Perceptions of interprofessional collaboration. Prof. Prof. 2014, 4, 1-16. [CrossRef]

69. Yatsco, A.J.; Champagne-Langabeer, T.; Holder, T.F.; Stotts, A.L.; Langabeer, J.R. Developing interagency collaboration to address the opioid epidemic: A scoping review of joint criminal justice and healthcare initiatives. Int. J. Drug Policy 2020, 83, 1-7. [CrossRef]

70. Oliver, C.; Mooney, A.; Statham, J. Integrated Working: A Review of the Evidence. 2010. Available online: https://dera.ioe.ac.uk/ 3674/1/Integrated_Working_A_Review_of_the_Evidence_report.pdf (accessed on 24 June 2021).

71. Gripp, C.; Jha, C.; Vaughn, P.E. Enhancing community safety through interagency collaboration: Lessons from Connecticut's Project Longevity. J. Law Med. Ethics 2020, 48, 47-54. [CrossRef] [PubMed]

72. Engel, R.S.; Tillyer, M.S.; Corsaro, N. Reducing gang violence using focused deterrence: Evaluating the Cincinnati Initiative to Reduce Violence (CIRV). Justice Q. 2013, 30, 403-439. [CrossRef]

73. Pullmann, M.D.; Kerbs, J.; Koroloff, N.; Veach-White, E.; Gaylor, R.; Sieler, D. Juvenile offenders with mental health needs: Reducing recidivism using wraparound. Crime Delinq. 2006, 52, 375-397. [CrossRef]

74. Department of Health. Equity and Excellence: Liberating the NHS. 2010. Available online: https://navigator.health.org. uk/theme/equity-and-excellence-liberating-nhs-white-paper?gclid=Cj0KCQjw2tCGBhCLARIsABJGmZ64nHDSPA_xpf34fSZUrFiIWuTq6gyHyRUKM8tv3mXYkENJQAY7UQaAioHEALw_wcB (accessed on 23 June 2021).

75. Murray, S.; Powell, A. Domestic Violence: Australian Public Policy; Australian Scholarly Publishing: Victoria, Australia, 2012.

76. Statham, J. A Review of International Evidence on Interagency Working, to Inform the Development of Children's Services Committees in Ireland. 2011. Available online: https:/ / www.lenus.ie/handle/10147/315237 (accessed on 24 June 2021). 
77. Stewart, S.L. Enacting entangled practice: Interagency collaboration in domestic and family violence work. Violence Women 2020, 26, 191-212. [CrossRef]

78. Cooper, M.; Evans, Y.; Pybis, J. Interagency collaboration in children and young people's mental health: A systematic review of outcomes, facilitating factors and inhibiting factors. Child Care Health Dev. 2015, 42, 325-342. [CrossRef] [PubMed]

79. Lamberti, J.S. Preventing criminal recidivism through mental health and criminal justice collaboration. Psychiatr. Serv. 2016, 67, 1206-1212. [CrossRef]

80. Noonan, P.M.; McCall, Z.A.; Zheng, C.; Gaumer Erickson, A.S. An analysis of collaboration in a state-level interagency transition team. Career Dev. Transit. Except. Individ. 2012, 35, 143-154. [CrossRef]

81. Green, B.L.; Rockhill, A.; Burns, S. The role of interagency collaboration for substance-abusing families involved with child welfare. Child Welf. 2008, 1, 29-61.

82. Kessing, D.; Denollet, J.; Widdershoven, J.; Kupper, N. Self-care and health-related quality of life in chronic heart failure: A longitudinal analysis. Eur. J. Cardiovasc. Nurs. 2017, 16, 605-613. [CrossRef] [PubMed]

83. Porporino, F.J. Bringing sense and sensitivity to corrections: From programmes to 'fix' offenders to services to support desistance. In What Else Works? Creative Work with Offenders; Brayford, J., Cowe, F., Deering, J., Eds.; Routledge: Oxford, UK, 2010; pp. 61-87. 